\title{
Life-conditions and anthropometric variables as risk factors for oral health in children in Ladakh, a cross-sectional survey
}

\author{
Maria Grazia Cagetti ${ }^{1}$, Fabio Cocco ${ }^{2}$, Ezio Calzavara ${ }^{3}$, Davide Augello ${ }^{3}$, Phunchok Zangpoo ${ }^{4}$ \\ and Guglielmo Campus ${ }^{2,5,6^{*}}$
}

\begin{abstract}
Background: The aim of this survey was to evaluate the severity of dental caries among children living in Zanskar Valley (Ladakh, India) and its association with anthropometric and background variables.

Methods: This cross-sectional survey was conducted on schoolchildren divided into four age groups $(<6, \geq 6<11, \geq 11<14$ and $>14$ years of age). A total of 1474 schoolchildren (607 males, 41.2\%) were examined. Actual caries prevalence (dt/DT) and gingival bleeding were recorded by four calibrated dentists. An ad hoc questionnaire evaluated general health, eating habits, oral hygiene and the self-perception of oral conditions. Height, weight, waist circumference, heart-rate and oxygen-saturation were also collected directly by examiners. Responses to questionnaire items were treated as categorical or ordinal variables. The relationship between children's caries data, gingival bleeding, gender, Body Mass Index (BMI) following the International Obesity Task Force, waist circumference and questionnaire items was assessed using the Kruskal-Wallis test and Pearson correlation. Conditional ordinal logistic regression was used to analyse associations among caries severity, gender, BMI, waist circumference, oxygen saturation and questionnaire items. A forward stepwise logistic regression procedure was also carried-out to estimate the ORs of gingival bleeding prevalence and the covariates derived from examination or questionnaire.

Results: Caries was almost ubiquitarian with only $10.0 \%$ of caries-free children (dt/DT $=0)$. Caries severity, in both primary and permanent dentitions, was statistically significantly related to gender, waist circumference, BMI, oral hygiene frequency and self-reported chewing problems ( $p<0.01$ in both dentitions). An increasing relative risk for caries in permanent dentition compared to caries-free subjects was observed in children with a low BMI $(R R R=1.67,95 \% \mathrm{Cl}=1.54 / 2.83$ for subjects with $1-3$ caries lesions and $\mathrm{RRR}=1.52,95 \% \mathrm{Cl}=1.36 / 1.74$ for subjects with $>3$ caries lesions); also, children with reduced waist circumference had a higher relative risk to have 1-3 caries lesions ( $\mathrm{RRR}=2.16,{ }_{95 \%} \mathrm{Cl}=1.84 / 2.53$ ) and an even higher risk to have more than 3 caries lesions $(\mathrm{RRR}=4.22$, $\left.{ }_{95 \%} \mathrm{Cl}=3.33 / 5.34\right)$.
\end{abstract}

Conclusions: A significant impact of untreated caries lesions was observed in Ladakh schoolchildren; low BMI values and reduced waist circumference showed to be the main caries risk predictors. Preventive and intervention programmes should be implemented to improve children's oral health.

Keywords: Oral health surveys, Dental caries, BMI, Waist circumference, Risk factors

*Correspondence: guglielmo.campus@zmk.unibe.ch

${ }^{5}$ Department of Restorative, Preventive and Pediatric Dentistry, University

of Bern, Freiburgstrasse 7, 3010 Bern, Switzerland

Full list of author information is available at the end of the article

\section{Background}

Ladakh is an Indian region, comprising two districts: Leh, with a Buddhist majority, and Kargil, with a Muslim majority, and a population of around 280 thousand 
inhabitants. The Indian Government reports Ladakh to be one of the districts below standards in term of health services and conditions $[1,2]$. The high altitude, above $9000 \mathrm{ft}$, is responsible for cold and an oxygen content equivalent to two thirds of that at sea level, limited diet, limited availability of drinking water with a low fluoride content $(\leq 0.02 \mathrm{ppm} / \mathrm{l})$ and poor socio-economic conditions [3-6]. Low obesity rates, physical growth patterns in height and arm circumference are reported [7-9].

Although great improvements have been made in global oral health, in the under-privileged populations such goal has not yet been achieved [10] and caries, in particular, is a health problem yet to be solved. Caries aetiology is a complex process with diet as one of its fundamental aetiological factors. Socio-environmental factors also play a strong role on oral health: they can produce damage to oral functions as well as affect the quality of life especially of disadvantaged groups of population. In developing countries, diet transition and inadequate exposure to fluorides are the main reasons for the growth of caries burden in these areas [11].

The Italian National Association of Dentists Foundation (ANDI) has among its main aims to improve the quality of life of populations with socio-economic inequalities in various parts of the world, as the population living in the Zanskar Valley of Ladakh. Dental care is limited to small dental clinic in Padum at the Community Health Center (CHC), the only hospital in the valley. During summertime, when the valley is accessible, teams of volunteers from ANDI Foundation work as dentists at the Zanskar Health Care \& Sowa Rigpa Research Institute facility and promote oral health in schools.

At the best of Authors' knowledge, no data regarding oral health of children living in Ladakh are available in literature. This epidemiological survey, in addition to filling this void, was conducted with the aim of collecting caries data in order to plan a preventive project to reduce caries through the use of Xylitol in children living in Ladakh.

The aim of the present survey was to assess the oral health conditions of a large sample of the children population aged from 5 to 17 years living in Zanskar Valley of Ladakh and to evaluate the association of oral variables with anthropometric measures, general health variables and life-style behaviours.

\section{Methods}

The survey was planned as a cross-section evaluation. The study was conducted in Summer 2019. The study population comprised schoolchildren aged 5-17 years.

\section{Study area and population}

The study was carried out from July to August 2019 in Zanskar Valley (Ladakh) in all the 18 schools (both public and private) located in and around the city of Padum, in some Buddhist monasteries and in some rural areas. Teachers from each involved school received a 2-h lesson on oral health prevention held in English, in the presence of a language mediator, in order for them to be able to teach this topic in class. The total schoolchildren population aged 5-17 years amounted to 2407 children. Due to language problems and the low literacy rate of the population, parents' or guardians' verbal approval was obtained for children's participation; verbal consent was also obtained by children capable to give assent (eight years old children and older). The only inclusion criteria for eligibility was to be between 5 and 17 years old and to obtain the verbal consent to participate from parents/ guardians or parents/guardian and child. No exclusions criteria were set. The study gained the approval of all the schools' authorities and local health authority. The response rate was $100 \%$.

\section{Data collection}

Due to the large number of subjects to be examined, four dentists acted as raters. Before leaving Italy, the team received training consisting in one-day theoretical course, followed by another day of examination of extracted teeth. Finally, a clinical training was performed on 20 children, who were examined and re-examined after $72 \mathrm{~h}$. Inter-examiner reliability, sensitivity, specificity, percentage agreement and kappa statistics were evaluated. Inter-examiner reliability ranged from 0.75 to 0.84 (K-Cohen) for sound and from 0.82 to 0.88 for caries lesions. Intra-examiner reliability ranged from 0.82 to 0.90 for sound teeth and from 0.84 to 0.91 for caries lesions. One examiner (EC) served as benchmark and conducted the theoretical and calibration sessions. During calibration, the team of examiners was also trained to measure and record the anthropometric indices. The Decayed-Missing-Filled (DMF and dmf) method proposed by WHO was used for caries lesion registration. The diagnostic threshold for the decayed tooth component $(d / D)$ is the cavitated dentine lesion $[12,13]$. Every subject was examined using: a plain mirror (Hahnenkratt, Königsbach, Germany) and the WHO CPI ballpoint probe (Asa-Dental, Milan, Italy), under standard light. When necessary, teeth were cleaned and/or dried using cotton rolls before the examination. No bitewing radiographs or fiber-optic trans-illumination were used. The presence of gingival bleeding after probing was evaluated only on six teeth [14].

An ad hoc questionnaire was build-up to assess general health, eating habits, oral hygiene and the self-perception of oral conditions, based on previous surveys (Additional file 1: Questionnaire) [15-18]. Direct face to face interviews were conducted with at least one parent of the 
children under the age of 12 , while older children were asked to answer a self-administered questionnaire. Ten items were related to dietary habits as the consumption of fresh fruit, biscuits, cakes, jam/honey, sweets/candy, meat, cheese, rice, chewing gum, soft drinks, sugared drinks; three items were related to hygiene habits as frequency of oral hygiene, use of a toothbrush and the perception of oral conditions.

The items related to general health (height, weight, waist circumference, heart-rate, oxygen saturation) were collected by the examiners as follows: the height $(\mathrm{cm})$ was measured using a portable stadiometer (Seca 700, DE, Seca.com) asking the children to stand upright with the back (head, buttocks and heels) touching the device, wearing the school uniform and no cap or shoes were admitted; the weight $(\mathrm{Kg})$ was also measured using a digital weight scale (Seca Clara 803, Seca, DE Seca.com); the waist circumference as the midway between lower ribs and the iliac crest was measured in $\mathrm{cm}$ after asking the children to stand with their arms wide open and feet positioned close together. The body mass index (BMI) was calculated dividing the weight by the height squared $\left(\mathrm{kg} / \mathrm{cm}^{2}\right)$; oxygen saturation and heart-rate were measured using a portable pulse oximetry device (Mindray PM-60, Mindray Medical Italy S.R.L).

The present study is reported according to the Reporting of Observational Studies in Epidemiology (Additional file 2: STROBE checklist) guidelines for cross-sectional studies [19].

\section{Statistical analysis}

Data were entered into a database (Excel 2018; Microsoft Corporation, Redmond, WA, USA). Statistical analyses were performed using Stata ${ }^{\circledR} 16.0$ software (http:// www.stata.com). Responses to questionnaire items were treated as categorical or ordinal variables. The BMI data and waist circumference were then considered by the ethnicity of the population, re-coded using the International Obesity Task Force [20-23] and then categorized into three categories each, as thinness (BMI below or equal to 15), normal weight (BMI more then 15 or lower then 22) and overweight (BMI more than 22) and as reduced less (than $64 \mathrm{~cm}$ ), normal $(64-71 \mathrm{~cm})$ and higher $(>71 \mathrm{~cm})$ for waist circumference. Oxygen saturation data was divided in two classes under $90 \%$ and above $90 \%$ [24].

Mean caries data, BMI, waist circumference and oxygen saturation were calculated by age groups $(<6, \geq 6<11, \geq 11<14$ and $>14$ years of age $)$. The relationship between children's caries data, gingival bleeding, gender, BMI, waist circumference and questionnaire items were assessed using the Kruskal-Wallis test and a linear trend was calculated to aid the interpretation of data to determine if the measurements indicate an increasing or decreasing trend. Caries severity was evaluated separately for primary and permanent dentition following the distribution frequencies as follows: $\mathrm{dt} / \mathrm{DT}=0$ (caries-free subjects), low caries severity $\mathrm{dt}$ in the range between 1 and 5 lesions, and DT in the range between 1 and 3 lesions, high caries severity $\mathrm{dt}>5$ and DT $>3$ caries lesions $[25,26]$. Conditional ordinal logistic regression was used to analyse associations among caries severity level (dt/DT) as dependent variable, gender, BMI, waist circumference, oxygen saturation and questionnaire items. The Akaike information criterion (AIC) was used to measure the goodness of fit of the statistical model. Multicollinearity might sometimes cause problems with regression results. This problem was solved using the DFBETA command in Stata, dropping the information that have too much influence on the regression line $[18$, 27].

A forward stepwise logistic regression procedure was also carried out to estimate the ORs of gingival bleeding prevalence and the covariates derived from clinical examination or questionnaire data.

\section{Results}

Overall, 1474 children (61.2\% of the population) were examined (Table 1), 607 males (41.2\%) and 867 females (58.8\%). All data are available as additional file (Additional 3: Raw data). The gender ratio was statistically different between living areas stratified by age group $\left(\chi^{2}{ }_{(6)}=56.6 p<0.01\right)$. Caries was almost ubiquitarian in the examined population with only $10.0 \%$ of children without caries lesions $(\mathrm{dt} / \mathrm{DT}=0)$ as is possible to read in Table 2. The highest mean number of caries lesions affecting primary dentition was recorded in younger groups (below 6 years of age and $\geq 6<11$ years of age), as in permanent dentition the highest values were observed in the oldest age group. Caries severity, both in primary and permanent dentitions was statistically significantly related to gender, waist circumference, $\mathrm{BMI}$, oral hygiene frequency and self-reported chewing problems $(p<0.01$ in both dentition), while oxygen saturation was statistically significantly related to caries severity in permanent dentition (Tables 3 and 4). For these variables, significant linear trends $(p<0.05)$ of caries severity were found in all exposure categories.

The main dietary habits consisted of rice $(95.5 \%$ of the sample reported to eat rice more than twice a day) and sugared drinks such as soft-drinks, kholak, sugared tea/ coffee $(96.9 \%$ of the sample reported more than twice a day). A statistically significant linear trend $\left(\mathrm{X}_{(3)}^{2}\right.$ linear trend $34.2 p<0.01)$ across the consumption of fruit was associated to caries severity (62.2\% at least once a day) (data not in table). 
Table 1 Sample distribution according to gender and living areas, stratified by age groups

\begin{tabular}{|c|c|c|c|c|c|}
\hline \multirow[t]{3}{*}{ Age groups } & \multirow[t]{3}{*}{ Gender } & \multicolumn{3}{|c|}{ Living areas } & \multirow{3}{*}{$\begin{array}{l}\text { Total } \\
\text { n (\%) }\end{array}$} \\
\hline & & Padum & Rural areas & Monastery & \\
\hline & & n (\%) & n (\%) & n (\%) & \\
\hline \multirow[t]{2}{*}{$<6$ years } & Males & 77 (27.3) & $45(16.0)$ & $2(0.71)$ & $124(44.0)$ \\
\hline & Females & $84(29.8)$ & $48(17.0)$ & $26(9.2)$ & $158(56.0)$ \\
\hline \multirow[t]{2}{*}{$\geq 6<11$ years } & Males & $123(25.6)$ & $68(14.1)$ & $19(4.0)$ & $210(43.7)$ \\
\hline & Females & $144(29.9)$ & $93(19.3)$ & $34(7.1)$ & $271(56.3)$ \\
\hline \multirow[t]{2}{*}{$\geq 11 \leq 14$ years } & Males & $116(26.0)$ & $61(13.7)$ & $15(3.4)$ & $192(43.0)$ \\
\hline & Females & 147 (32.9) & $103(23.0)$ & $5(1.1)$ & $255(57.1)$ \\
\hline \multirow[t]{3}{*}{$>14$ years } & Males & $56(21.2)$ & $18(6.8)$ & $7(2.6)$ & $81(30.7)$ \\
\hline & Females & $150(56.8)$ & $32(12.1)$ & $1(0.4)$ & $183(69.2)$ \\
\hline & Total & 897 (60.9) & 468 (31.8) & $109(7.4)$ & $1474(100.0)$ \\
\hline
\end{tabular}

Males versus females by age-groups $x_{(3)}^{2}=14.72 p<0.01$

Males versus females by living areas $X_{(6)}^{2}=56.62 p<0.01$

Table 2. Descriptive valued of BMI, waist circumference adjusted by age, oxygen saturation, caries indices (dt/DT, mt/MT, ft/FT, dmft/DMFT) stratified by age-groups.

\begin{tabular}{|c|c|c|c|c|}
\hline \multicolumn{5}{|c|}{ Mean value, Standard Deviation (SD) } \\
\hline & $<6$ years of age $(n=282)$ & $\begin{array}{l}\geq 6<11 \text { years of age } \\
(n=481)\end{array}$ & $\begin{array}{l}\geq 11 \leq 14 \text { years of age } \\
(n=447)\end{array}$ & $\begin{array}{l}>14 \text { years } \\
\text { of age } \\
(n=264)\end{array}$ \\
\hline & Mean (SD) & Mean (SD) & Mean (SD) & Mean (SD) \\
\hline \multicolumn{5}{|l|}{ BMI (IOTF) } \\
\hline Thinness ( $\leq 15)$ & $13.6(1.9)$ & $13.96(1.4)$ & $13.9(0.9)$ & $13.7(0.5)$ \\
\hline Normal weight (>15 $\leq 22)$ & $16.2(1.1)$ & $16.3(1.3)$ & $17.3(1.6)$ & $18.9(1.6)$ \\
\hline Overweight(> 22) & $26.2(5.5)$ & $28.0(5.1)$ & $24.5(1.3)$ & $23.3(1.5)$ \\
\hline \multicolumn{5}{|l|}{ Waist circumference } \\
\hline Reduced $(<64)$ & $55.0(3.9)$ & $57.4(3.5)$ & $59.9(4.0)$ & $57.1(6.5)$ \\
\hline Normal (64-71) & $66.1(2.0)$ & $66.6(2.2)$ & $67.2(2.2)$ & $68.5(2.2)$ \\
\hline Higher $(<71)$ & $74.5(2.4)$ & $74.4(2.4)$ & $76.9(4.2)$ & $78.3(4.3)$ \\
\hline \multicolumn{5}{|l|}{$\mathrm{O}_{2}$ saturation } \\
\hline Under 90\% & $84.4(5.8)$ & $83.5(7.2)$ & $83.4(12.1)$ & $86.1(3.2)$ \\
\hline Above $90 \%$ & $93.6(2.5)$ & $94.5(2.6)$ & $94.3(3.0)$ & $93.8(2.7)$ \\
\hline $\mathrm{dt}$ & $6.4(4.2)$ & $5.0(3.5)$ & $0.9(1.5)$ & $0.1(0.6)$ \\
\hline DT & $0.2(0.6)$ & $1.0(1.2)$ & $1.9(2.3)$ & $2.5(2.4)$ \\
\hline $\mathrm{mt}$ & $-(-)$ & $-(-)$ & $-(-)$ & $-(-)$ \\
\hline MT & $-(-)$ & $-(-)$ & $-(-)$ & $0.69(0.2)$ \\
\hline $\mathrm{ft}$ & $0.2(0.1)$ & $0.5(0.14)$ & $0.1(0.3)$ & $0.1(0.5)$ \\
\hline FT & $-(-)$ & $0.0 .1(0.3)$ & $0.4(0.7)$ & $0.20(1.1)$ \\
\hline $\mathrm{dmt}$ & $6.6(4.4)$ & $5.4(3.7)$ & $1.0(1.8)$ & $0.1(0.8)$ \\
\hline DMFT & $0.2(0.6)$ & $1.1(1.4)$ & $2.3(2.3)$ & $3.3(2.7)$ \\
\hline
\end{tabular}

Estimates related to caries severity in primary and permanent dentitions according to gender, waist circumference, BMI, oral hygiene frequency, self-reported chewing problems, oxygen saturation and sugared foods and drinks consumption (the latter two related to permanent dentition) are displayed in Table 5 without outliers. All the models were statistically significant $(p<0.01)$. An increasing relative risk for caries in permanent dentition compared to caries-free subjects was observed in children with a low BMI $(R R R=1.7$, 
Table 3 Sample distribution by gender, waist circumference adjusted by age, BMI, oral hygiene frequency and Selfreported chewing problem stratified by caries lesions categorization in primary dentition

\begin{tabular}{|c|c|c|c|}
\hline \multicolumn{4}{|l|}{ Number of subjects $=916$} \\
\hline \multirow[t]{2}{*}{ Gender } & 0 caries lesions & $1-5$ caries lesions & $>5$ caries lesions \\
\hline & n (\%) & n (\%) & n (\%) \\
\hline Males & $132(14.4)$ & $130(14.2)$ & $115(12.6)$ \\
\hline Females & $255(27.8)$ & $173(18.9)$ & $111(12.1)$ \\
\hline \multirow[t]{2}{*}{ Waist circumference } & 0 caries lesions & $1-5$ caries lesions & $>5$ caries lesions \\
\hline & n (\%) & n (\%) & n (\%) \\
\hline Reduced & $77(8.4)$ & $219(23.9)$ & $198(21.6)$ \\
\hline Normal & $123(13.4)$ & $66(7.2)$ & $24(2.6)$ \\
\hline Higher & $187(20.4)$ & $17(1.9)$ & $5(0.6)$ \\
\hline \multirow[t]{2}{*}{ BMI (IOTF classification) } & 0 caries lesions & $1-5$ caries lesions & $>5$ caries lesions \\
\hline & n (\%) & n (\%) & n (\%) \\
\hline Thinness & $108(11.8)$ & $113(12.3)$ & $105(11.5)$ \\
\hline Normal & $268(29.3)$ & $175(19.1)$ & $109(11.9)$ \\
\hline Over weight & $12(1.3)$ & $14(1.5)$ & $13(1.4)$ \\
\hline \multirow[t]{2}{*}{ Oral hygiene frequency } & 0 caries lesions & $1-5$ caries lesions & $>5$ caries lesions \\
\hline & n (\%) & n (\%) & n (\%) \\
\hline Seldom & $14(1.5)$ & $40(4.8)$ & $48(5.2)$ \\
\hline Less once a day & $47(5.1)$ & $55(6.0)$ & $52(5.7)$ \\
\hline Once a day & $218(23.8)$ & $135(14.7)$ & $86(9.4)$ \\
\hline Twice/day & 109 (11.9) & $72(7.9)$ & $40(4.4)$ \\
\hline \multirow[t]{2}{*}{ Self-reported chewing problem } & 0 caries lesions & $1-5$ caries lesions & $>5$ caries lesions \\
\hline & n (\%) & n (\%) & n (\%) \\
\hline No & $4(0.4)$ & $12(1.3)$ & $17(1.9)$ \\
\hline Seldom & 108 (11.8) & $87(9.5)$ & $65(7.1)$ \\
\hline Often & $275(30.0)$ & $205(22.4)$ & $143(15.6)$ \\
\hline
\end{tabular}

$X_{(1)}^{2}$ linear trend $=27.07 p<0.01$

$X_{(2)}^{2}$ linear trend $543.46 p<0.01$

$X^{2}{ }_{(2)}$ linear trend $43.70 p<0.01$

$X^{2}{ }_{(3)}$ linear trend $114.12 p<0.01$

$X^{2}{ }_{(2)}$ linear trend $28.36 p<0.01$

95\% $\mathrm{CI}=1.5 / 2.8$ for subjects with $1-3$ caries lesions and $\mathrm{RRR}=1.5,{ }_{95 \%} \mathrm{CI}=1.4 / 1.7$ for subjects with more than 3 caries lesions); children with reduced waist circumference also had a higher relative risk of having 1-3 caries lesions $\left(\mathrm{RRR}=2.2,{ }_{95 \%} \mathrm{CI}=1.8 / 2.5\right)$ and an even higher risk of having more than 3 caries lesions $(R R R=4.2$, ${ }_{95 \%} \mathrm{CI}=3.3 / 5.3$ ). The goodness of fit (AIC criterion) was 4012.7. Table 6 presents the OR estimates via the forward procedures in logistic regression by gingival bleeding. Subjects with reduced waist circumference were found to have twice the risk of gingival bleeding; also subjects with reduced oxygen saturation showed an increased risk of gingival bleeding $(\mathrm{OR}=1.8$ $\left.{ }_{95 \%} \mathrm{CI}=1.6 / 2.4\right)$.

\section{Discussion}

This is the first epidemiological survey carried out in an isolated valley of the remote region of Ladakh, which contributes to the characterization of oral health of a particular population of children living in an area where environmental conditions are extremely difficult. The oral conditions, weight and height, waist circumference, oxygen saturation, heart-rate and dietary and oral hygiene habits of about two thirds of the entire school population were examined at school.

For both dentitions, caries prevalence was very high in all age groups, for both genders and for different living areas. Caries experience was entirely due to decayed teeth, since fillings were few in all age groups. 
Table 4 Sample distribution by gender, waist circumference adjusted by age, BMI, oxygen saturation, sugared foods and drinks, oral hygiene frequency and Self-reported chewing problem stratified by caries lesions categorization in permanent dentition

\begin{tabular}{|c|c|c|c|}
\hline \multicolumn{4}{|l|}{ Number of subjects $=1248$} \\
\hline \multirow[t]{2}{*}{ Gender } & 0 caries lesions & $1-3$ caries lesions & $>3$ caries lesions \\
\hline & n (\%) & n (\%) & n (\%) \\
\hline Males & $274(22.0)$ & $187(15.0)$ & $53(4.3)$ \\
\hline Females & $264(26.2)$ & $307(24.6)$ & $101(8.1)$ \\
\hline \multirow[t]{2}{*}{ Waist circumference } & 0 caries lesions & 1-3 caries lesions & $>3$ caries lesions \\
\hline & n (\%) & n (\%) & n (\%) \\
\hline Reduced & $429(34.4)$ & $212(17.0)$ & $31(2.5)$ \\
\hline Normal & $93(7.45)$ & $150(12.0)$ & $47(3.8)$ \\
\hline Higher & $77(6.17)$ & $132(10.6)$ & $75(6.0)$ \\
\hline \multirow[t]{2}{*}{ BMI (IOTF classification) } & 0 caries lesions & 1-3 caries lesions & $>3$ caries lesions \\
\hline & n (\%) & n (\%) & n (\%) \\
\hline Thinness & $212(17.0)$ & $181(14.5)$ & $51(4.1)$ \\
\hline Normal & $353(28.3)$ & $298(23.9)$ & $99(7.9)$ \\
\hline Over weight & $36(2.9)$ & $14(1.1)$ & $3(0.2)$ \\
\hline \multirow[t]{2}{*}{ Oxygen Saturation } & 0 caries lesions & $1-3$ caries lesions & $>3$ caries lesions \\
\hline & n (\%) & n (\%) & n (\%) \\
\hline$\leq 90 \%$ & $238(19.1)$ & $218(17.5)$ & $72(5.8)$ \\
\hline$>90 \%$ & $362(29.0)$ & $277(22.2)$ & $81(6.5)$ \\
\hline \multirow[t]{2}{*}{ Oral Hygiene Frequency } & 0 caries lesions & 1-3 caries lesions & $>3$ caries lesions \\
\hline & n (\%) & n (\%) & n (\%) \\
\hline Seldom & $88(7.1)$ & $41(3.3)$ & $9(0.7)$ \\
\hline Less once a day & $110(8.8)$ & $86(6.9)$ & $14(1.1)$ \\
\hline Once a day & $252(20.2)$ & $254(20.3)$ & $93(7.5)$ \\
\hline Twice/day & 149 (11.9) & $114(9.1)$ & $37(3.0)$ \\
\hline \multirow[t]{2}{*}{ Sugared foods and drinks } & 0 caries lesions & $1-3$ caries lesions & $>3$ caries lesions \\
\hline & n (\%) & n (\%) & n (\%) \\
\hline Seldom & $3(0.24)$ & $6(0.48)$ & $-(-)$ \\
\hline Once a day & $311(24.9)$ & $279(22.4)$ & $77(6.2)$ \\
\hline More than once a day & $286(22.9)$ & $210(16.8)$ & $76(6.1)$ \\
\hline \multirow[t]{2}{*}{ Self-reported chewing problem } & 0 caries lesions & 1-3 caries lesions & $>3$ caries lesions \\
\hline & n (\%) & n (\%) & n (\%) \\
\hline No & $30(2.4)$ & $14(1.1)$ & $1(0.1)$ \\
\hline Seldom & $140(11.2)$ & $156(12.5)$ & $57(4.6)$ \\
\hline Often & $430(34.5)$ & $324(26.0)$ & $95(7.6)$ \\
\hline
\end{tabular}

$X_{(1)}^{2}$ linear trend $=12.19 p<0.01$

$X_{(2)}^{2}$ linear trend $=202.41 p<0.01$

$X_{(2)}^{2}$ linear trend $=9.25 p<0.01$

$X^{2}{ }_{(1)}$ linear trend $=4.37 p=0.04$

$X_{(3)}^{2}$ linear trend $=33.13 p<0.01$

$X^{2}{ }_{(2)}$ linear trend $=0.53 p=0.75$

$X_{(2)}^{2}$ linear trend $=25.53 p<0.01$ 
Table 5. Multivariate analysis. Conditional multinomial regression between caries lesions categorization and background variables

\begin{tabular}{|c|c|c|c|c|c|c|}
\hline \multicolumn{7}{|c|}{ In brackets is reported the reference of each background variable } \\
\hline \multicolumn{7}{|l|}{ Primary dentition } \\
\hline Number of observation $=916$ & \multirow{2}{*}{\multicolumn{2}{|c|}{$x_{(8)}^{2}=706.16$}} & \multicolumn{2}{|c|}{$p<0.01$} & \multicolumn{2}{|c|}{ log likelihood $=-1231.86$} \\
\hline \multicolumn{5}{|l|}{ Base outcome caries-free subjects } & & \\
\hline & \multicolumn{3}{|c|}{ Low caries severity } & \multicolumn{3}{|c|}{ High caries severity } \\
\hline & RRR (SE) & $p>|z|$ & $95 \% \mathrm{Cl}$ & RRR (SE) & $p>|z|$ & $95 \% \mathrm{Cl}$ \\
\hline Gender (male) & $0.8(0.1)$ & 0.12 & $0.6 / 1.1$ & $1.6(0.2)$ & $<0.01$ & $1.4 / 2.8$ \\
\hline Waist circumference (reduced) & $2.2(0.1)$ & $<0.01$ & $1.2 / 3.2$ & $1.4(0.1)$ & $<0.01$ & 2.1/4.1 \\
\hline BMI (thinness) & $1.3(0.2)$ & 0.03 & $1.0 / 1.8$ & $1.1(0.2)$ & 0.53 & $0.8 / 1.5$ \\
\hline Oral Hygiene Frequency (seldom) & $1.8(0.2)$ & $<0.01$ & $1.6 / 2.9$ & $1.6(0.2)$ & $<0.01$ & $1.5 / 3.2$ \\
\hline \multicolumn{7}{|l|}{ Permanent dentition } \\
\hline Number of observation $=1248$ & \multirow{2}{*}{\multicolumn{2}{|c|}{$x_{(14)}^{2}=240.22$}} & \multirow{2}{*}{\multicolumn{2}{|c|}{$p<0.01$}} & \multirow{2}{*}{\multicolumn{2}{|c|}{ log likelihood $=-1318.35$}} \\
\hline Base outcome caries-free subjects & & & & & & \\
\hline & \multicolumn{3}{|c|}{ Low caries severity } & \multicolumn{3}{|c|}{ High caries severity } \\
\hline & RRR (SE) & $p>|z|$ & $95 \% \mathrm{Cl}$ & RRR (SE) & $p>|z|$ & $95 \% \mathrm{Cl}$ \\
\hline Gender (male) & $1.2(0.2)$ & 0.09 & $1.0 / 1.5$ & $1.3(0.2)$ & 0.21 & $0.9 / 1.8$ \\
\hline Waist circumference (reduced) & $2.2(0.2)$ & $<0.01$ & $1.8 / 2.5$ & $4.2(0.5)$ & $<0.01$ & $3.3 / 5.3$ \\
\hline BMI (thinness) & $1.7(0.2)$ & $<0.01$ & $1.5 / 2.8$ & $1.5(0.1)$ & $<0.01$ & 1.4/1.7 \\
\hline O2 saturation $(\leq 90 \%)$ & $1.2(0.1)$ & 0.07 & $1.0 / 1.0$ & $1.0(0.1)$ & 0.05 & $1.0 / 1.0$ \\
\hline Oral Hygiene Frequency (seldom) & $1.1(0.1)$ & 0.44 & $0.9 / 1.2$ & $1.4(0.1)$ & 0.24 & $0.9 / 1.4$ \\
\hline Sugared foods/drinks (seldom) & $1.8(0.1)$ & 0.01 & 1.6/1.9 & $1.0(0.2)$ & 0.94 & $0.7 / 1.4$ \\
\hline Self-reported chewing problem (yes) & $0.8(0.1)$ & 0.08 & $0.7 / 1.0$ & $1.1(0.1)$ & 0.05 & $1.0 / 1.2$ \\
\hline
\end{tabular}

The bold values represent the statistically significant results

Table 6 Multivariate analysis. Logistic regression between bleeding on probing and background variables

\begin{tabular}{|c|c|c|c|}
\hline \multicolumn{2}{|l|}{ Number of observation $=1474$} & \multicolumn{2}{|c|}{$X_{(6)}^{2}=24.90 p<0.01$ log likelihood $=-931.25$} \\
\hline Bleeding on probing & OR (SE) & $p>|z|$ & $95 \% \mathrm{Cl}$ \\
\hline Waist circumference (reduced) & $2.2(0.2)$ & $<0.01$ & $1.8 / 2.5$ \\
\hline BMI (underweight) & $0.9(0.1)$ & 0.07 & $0.7 / 1.0$ \\
\hline $\mathrm{O}_{2}$ saturation $(\leq 90 \%)$ & $1.8(0.2)$ & 0.01 & $1.6 / 2.4$ \\
\hline Oral Hygiene Frequency (seldom) & $1.1(0.1)$ & 0.27 & $0.1 / 1.2$ \\
\hline Sugared foods/drinks (seldom) & $1.2(0.1)$ & 0.09 & $0.1 / 1.5$ \\
\hline Self-reported chewing problem (yes) & $0.8(0.1)$ & 0.08 & $0.7 / 1.0$ \\
\hline
\end{tabular}

The bold values represent the statistically significant results

A weak point of the survey could regard the caries index used (DMFT):it is not designed to record additional caries data such as the activity of the lesion or the extreme consequences of the caries process, as fistula or abscess [13]. On the other hand, the high number of children enrolled and the location of the examination (schools) calls for the use of an easy and quick method to record caries, such as the DMFT index.

There were more females than males in the sample; in the older group ( $>14$ years) males in particular, represented less than a third of the sample. Two different hypotheses can be made to explain this gender disparity: the early school leaving of males caused by their 
involvement in work activities, as reported in previous studies $[29,30]$, or their transfer to more prestigious schools outside the Valley, as families prefer to invest on the education of boys rather than girls [31].

Few data are available on caries in children population with similar background characteristics. While Nepalese schoolchildren showed a high caries prevalence in both dentitions with values lower than those recorded in Ladakh [32], the caries prevalence in Mongolian adolescents was higher, although the sample size was quite reduced [33]. Caries severity, as the number of dentine caries lesions for both dentitions, was associated to gender, waist circumference, BMI, oral hygiene frequency and self-reported chewing related problems. A rather large number of papers investigated the association between caries and anthropometric variables [33-35]. Children and adolescents living in high altitude areas present lower growth patterns than their counterparts living at sea level [6]. The Body Mass Index provides a convenient measure of a person's fatness. The BMI proposed by the International Obesity Task Force (IOTF) was used to assess the prevalence of child overweight, obesity and thinness, as it provides more effective values of thinness especially in populations with a high prevalence of under-weight children [20]. No agreement is reported in literature on the relationship between BMI and dental caries due to the effect of confounders and effect modifiers [28]. Furthermore, in most of the studies, BMI was calculated according to the World Health Organization guidelines. Although evidence of the coexistence of obesity and dental caries has been reported, as the same risk factors are shared, a U-shaped relationship between severe dental caries and the two ends of anthropometric measures has been reported in Chinese children [29]. Dental caries was more common among low weight Indian children than among normal weight and overweight-obese children [30]. According to these findings, Ladakh children in the thinness BMI category and with a low waist circumference present a higher risk rate of caries than their peers with normal or high anthropometric variables. Waist circumference as well as $\mathrm{BMI}$ index, have shown to predict the clustering risk factor of cardiovascular disease and coronary artery disease $[35,36]$. Since no longitudinal studies have examined the association between severe dental caries and both thinness and overweight, it is difficult to give reasons for their observed association. Overweight/obesity and thinness are different sides of the same coin: malnutrition. High intakes of saturated fat, sugared drinks and snacks, and refined carbohydrates intake produce overweight, whilst low intakes of foods rich in vitamins and proteins may cause thinness. This scarcity of highly nutritious foods is replaced by foods rich in sugars. In both cases, an inadequate intake of free-sugars may represent a risk for dental health, especially when protective caries factors are missing [37]. Waist circumference was also associated to gingival health: children with a reduced waist circumference show a double risk of bleeding on probing compared to normal or high values. However, BMI was not associated with bleeding, making the association between gingival bleeding and malnutrition unclear. A limited diet, low in fresh fruit and vegetables, is a factor influencing malnutrition, especially with regard to dietary intake of vitamins. In a recent metanalysis investigating the role of vitamins on oral health, vitamin $\mathrm{C}$ deficiency was found to be associated with gum bleeding; a reduction of the gingival problem was recorded after vitamin supplementation [38]. Obesity has been linked to increased inflammatory activity in gingival fluid [36] and obese children with Type 2 diabetes show a trend towards poorer oral health compared to normal weight and obese children without diabetes [39]. As far as the Authors know, this is the first paper that found an association between gingival health and low anthropometric values.

Poor oral hygiene habits are recognized as a risk factor both for caries and gingivitis in children and adults [14, $16,40,41$. In childhood, behavioural changes in relation to hygiene habits can have an important influence on the oral health status of future adults [40]. About a quarter of the children in Zanskar valley of Ladakh, with both primary and permanent dentitions, brush their teeth less frequently than once a day; this poor habit increases the risk for caries, especially in younger children. Both pre-school children and adolescents who brushed their teeth more than once daily showed less caries experience than those who brushed their teeth once per day [42, 43]. These outcomes could be related to several factors among which the poor knowledge of hygienic standards and the lacking availability of many imported consumer products, such as toothbrushes and toothpastes.

\section{Conclusions}

This survey highlights to what extent oral health can be considered a burdensome issue in the children population of a remote area of India. Anthropometric variables linked to malnutrition (i.e. low BMI and reduced waist circumference) and poor oral hygiene habits were associated with a high prevalence of untreated dental caries leading to frequent chewing problems. Effective preventive programmes need to be implemented at school-level to improve oral health of children living in Ladakh. 


\section{Supplementary Information}

The online version contains supplementary material available at https://doi. org/10.1186/s12903-021-01407-4.

Additional file 1. Questionnaire.

Additional file 2. STROBE Checklist.

Additional file 3. Raw data.

\section{Abbreviations}

dmft: Decayed, missed, filled teeth (primary dentition); DMFT: Decayed, missed, filled teeth (permanent dentition); CPI: Community Periodontal Index; RRR: Relative risk ratio; 95\%Cl: 95\% Confidence interval; BMI: Body Mass Index; IOTF: International obesity task force; WHO: World Health Organization; ORs: Odds ratio.

\section{Acknowledgements}

The authors want to thank the ANDI (Italian Association of Italian Dentists) Foundation for the support provided for the survey, the volunteers of ANDI Foundation and the authorities in Ladakh for helping us to perform the surveys. In particular, the authors want to thank the Zanskar Health Care \& Sowa Rigpa Research Institute and Dr. Enrico Carlino, supporting the survey.

\section{Authors' contributions}

MGC: designed the survey, performed the papers validity assessment and drafting the manuscript; FC: performed the data analysis, realized tables and contributed to write the manuscript; EC: participated to the survey, data collection; DA: performed data collection; PZ: help to organized the survey; GC: designed the survey, checked data analysis and drafting the manuscript. All authors read and approved the final version of the manuscript.

\section{Funding}

No funding was obtained for this study.

\section{Availability of data and materials}

All data generated or analysed during this study are included in this published article and/or in additional files. The data were available as Additional file 3 : Raw data.

\section{Ethics approval and consent to participate}

No official Ethical committee was present in the area of the survey. The study proposal was submitted to the Block Medical Officer, Zanskar and authorities of the Zanskar Health Care \& Sowa Rigpa Research Institute (ZHCSRRI) and its coordinator the Lama Zotpa. Both the Block Medical Officer and the coordinator of ZHCSRRI gave the approval for the study. Each school involved in the survey also gave the approval for participation. Due to language problems and the low literacy rate of the population, parents or guardians verbal approval was obtained for children's participation. Verbal approval was also obtained by each child. The study was conducted in accordance with the Declaration of Helsinki on Ethical Principles for Medical Research Involving Human Subjects.

\section{Consent for publication}

Not applicable.

\section{Competing interests}

The authors declare that they have no competing interests. There are no financial completing interests as we have not received any grants. The authors alone are responsible for the content and writing of the paper.

\section{Author details}

${ }^{1}$ Department of Biomedical, Surgical and Dental Science, University of Milan, Via Beldiletto 1, 20142 Milan, Italy. ${ }^{2}$ Department of Surgery, Microsurgery and Medicine Sciences, School of Dentistry, University of Sassari, Viale San Pietro, 07100 Sassari, Italy. ${ }^{3}$ Private Practitioner, Italian Association of Dentists (ANDI) Foundation Onlus, Via Giuseppe Ripamonti 44, 20141 Milan, Italy. ${ }^{4}$ Dental Surgeon, Community Health Center, Padum, Zanskar, Ladakh, c/o Italian Association of Dentists (ANDI) Foundation Onlus, Via Giuseppe Ripamonti 44, 20141 Milan, Italy. ${ }^{5}$ Department of Restorative, Preventive and Pediatric
Dentistry, University of Bern, Freiburgstrasse 7, 3010 Bern, Switzerland. ${ }^{6}$ School of Dentistry, Sechenov University, 119991 Moscow, Russia.

Received: 9 April 2020 Accepted: 24 January 2021

Published online: 05 February 2021

\section{References}

1. Sherratt, K. Social and Economic Characteristics of Ladakh, India. Available online: https://www.geolsoc.org.uk/media/shared/documents/Events/ Past Meeting Resources/Himalaya 14 Cultural Background to Ladakh.pdf Accessed 21 March 2020.

2. Taneja G, Sridhar VS-R, Mohanty JS, Joshi A, Bhushan P, Jain M, Gupta S, Khera A, Kumar, Gera RR. India's RMNCH+A Strategy approach, learnings and limitations. BMJ Glob Health. 2019;4:e001162.

3. Miele $\mathrm{CH}$, Schwartz AR, Gilman RH, Pham L, Wise RA, Davila-Roman VG, Jun JC, Polotsky VY, Miranda JJ, Leon-Velarde F, Checkley W. Increased cardiometabolic risk and worsening hypoxemia at high altitude. High Alt Med Biol. 2016:17:93-100.

4. Hirschler V, Molinari C, Gonzalez C, Maccallini G, Castano LA. Prevalence of hypertension in argentinean indigenous children living at high altitudes versus US children. Clin Exp Hypertens. 2018;40:752-7.

5. Hirschler V, Gonzalez C, Molinari C, Velez H, Nordera M, Suarez R, Robredo A. Blood pressure level increase with altitude in three argentinean indigenous communities. AIMS Public Health. 2019:6:370-9.

6. Angchok D, Dwivedi SK, Ahmed Z. Traditional foods and beverages of Ladakh. Indian J Tradit Know. 2009:8:551-8.

7. Cossio-Bolaños MA, Sanchez-Macedo L, Lee Andruske C, Fuentes-López J, Limachi-Flores M, Apaza-Cruz J, Mamani-Velásquez D, Mamani-Luque O, Sulla-Torres J, Gomez-Campos R. Physical growth and body adiposity patterns in children and adolescents at high altitudes in Peru: Proposed percentiles for assessment. Am J Hum Biol. 2020:e23398.

8. Santos C, Bustamante A, Katzmarzyk PT, Vasconcelos O, Garganta R, Freitas D, Mirzaei-Salehabadi S, Maia J. Growth velocity curves and pubertal spurt parameters of Peruvian children and adolescents living at different altitudes. The Peruvian health and optimist growth study. Am J Hum Biol. 2019:31:e23301.

9. Khan Y, Khan N. Nutritional status of children 0-24 months In Jammu Kashmir and Ladakh Regions. Int J Sci Res Publ. 2012;2:225-31.

10. GBD 2017 Oral Disorders Collaborators. Global, Regional, and National Levels and Trends in Burden of Oral Conditions from 1990 to 2017: A Systematic Analysis for the Global Burden of Disease 2017 Study. J Dent Res. 2020;99:362-73.

11. Bourgeois DM, Llodra JC. Global burden of dental condition among children in nine countries participating in an international oral health promotion programme, 2012-2013. Int Dent J. 2014;64:27-34.

12. WHO (World Health Organization). Oral Health Surveys: Basic Methods, 5th ed. Monts, France: WHO; 2013.

13. Campus G, Cocco F, Ottolenghi L, Cagetti MG. Comparison of ICDAS, CAST, Nyvad's Criteria, and WHO-DMFT for caries detection in a sample of Italian schoolchildren. Int J Environ Res Public Health. 2019;16(21).

14. Ainamo J, Barmes D, Beagrie G, Cutress T, Martin J, Sardo-Inifiri J. Development of the World Health Organization (WHO) Community Periodontal Index of Treatment Needs (CPITN). Int Dent J. 1982;32:281-91.

15. Campus G, Solinas G, Cagetti MG, Senna A, Minelli L, Majori S, Montagna MT, Reali D, Castiglia P, Strohmenger L. National Pathfinder survey of 12-year-old Children's Oral Health in Italy. Caries Res. 2007;41:512-7.

16. Lara-Capi C, Cagetti MG, Cocco F, Lingström P, García-Godoy F, Campus G. Effect of body weight and behavioural factors on caries severity in Mexican rural and urban adolescents. Int Dent J. 2018:683:190-6.

17. Cagetti MG, Congiu G, Cocco F, Meloni G, Sale S, Campus G. Are distinctive risk indicators associated with different stages of caries in children? A cross-sectional study. BMC Public Health. 2016;1(161):1213.

18. Majorana A, Cagetti MG, Bardellini E, Amadori F, Conti G, Strohmenger $\mathrm{L}$, Campus $\mathrm{G}$. Feeding and smoking habits as cumulative risk factors for early childhood caries in toddlers, after adjustment for several behavioral determinants: a retrospective study. BMC Pediatr. 2014;14:45.

19. Vandenbroucke JP, von Elm E, Altman DG, Gøtzsche PC, Mulrow CD, Pocock SJ, Poole C, Schlesselman JJ, Egger M. STROBE Initiative. 
Strengthening the Reporting of Observational Studies in Epidemiology (STROBE): explanation and elaboration. PLoS Med 2007; 4: e297.

20. Cole TJ, Lobstein T. Extended international (IOTF) body mass index cutoffs for thinness, overweight and obesity. Pediatr Obes. 2012;7:284-94.

21. Partap U, Young EH, Allotey P, Sandhu MS, Reidpath DD. The use of different international references to assess child anthropometric status in a Malaysian population. J Pediatr. 2017;190:63-8.

22. Santos C, Bustamante A, Hedeker D, Vasconcelos O, Garganta R, Katzmarzyk PT, Maia J. Correlates of Overweight in Children and Adolescents Living at Different Altitudes: The Peruvian Health and Optimist Growth Study. J Obes. 2019:2631713.

23. ColeTJ, Flegal KM, Nicholls D, Jackson AA. Body mass index cut-offs to define thinness in children and adolescents: international survey. BMJ. 2007;335:194-97.

24. Subhi R, Smith K, Duke T. When should oxygen be given to children at high altitude? A systematic review to define altitude-specific hypoxaemia. Arch Dis Child. 2009;94:6-10.

25. Lesaffre E, Mwalili SM, Declerck D. Analysis of caries experience taking inter-observer bias and variability into account. J Dent Res. 2004;83:951-5

26. Campus G, Cagetti MG, Senna A, Spano G, Benedicenti S, Sacco G. Differences in oral health among Italian adolescents related to the type of secondary school attended. Oral Health Prev Dent. 2009;7:323-30.

27. Bollen KA, Jackman RW. Regression diagnostics: an expository treatment of outliers and influential cases. SMR. 1985;13:510-42.

28. Flisher AJ, Townsend L, Chikobvu P, Lombard CF, King G. Substance use and psychosocial predictors of high school dropout in Cape Town. South Africa J Res Adol. 2010;20:237-55.

29. Weybright EH, Caldwell LL, Xie HJ, Wegner L, Smith EA. Predicting secondary school dropout among South African adolescents: A survival analysis approach. S Afr J Educ. 2017:37:1353.

30. Siddhu $\mathrm{G}$. Who makes it to secondary school? Determinants of transition to secondary schools in rural India. Int J Edul Develop. 2011;31:394-401.

31. Karki S, Laitala ML, Humagain M, Seppänen M, Päkkila J, Anttonen V. Oral health status associated with sociodemographic factors of Nepalese schoolchildren: a population-based study. Int Dent J. 2018;68:348-58.

32. Shivakumar S, Srivastava A, C Shivakumar G. Body Mass Index and Dental Caries: A Systematic Review. Int J Clin Pediatr Dent. 2018;11:228-32.

33. Reddy VP, Reddy VC, Krishna Kumar RVS, Sudhir KM, Srinivasulu G, Deepthi A. Dental caries experience in relation to body mass index and anthropometric measurements of rural children of Nellore district: a cross-sectional study. J Indi Soc Pedod Prev Dent. 2019:37:12-7.

34. Janssen I, Katzmarzyk PT, Srinivasan SR, Chen W, Malina RM, Bouchard C, Berenson GS. Combined influence of body mass index and waist circumference on coronary artery disease risk factors among children and adolescents. Pediatrics. 2005;115:1623-30.
35. Fernandez JR, Redden DT, Pietrobelli A, Allison DB. Waist circumference percentiles in nationally representative samples of African-American, European-American, and Mexican-American children and adolescents. J Pediatr. 2004;145:439-44.

36. Zuza EC, Pires JR, de Almeida AA, Toledo BEC, Guimaraes-Stabili MR, Junior CR. Barroso EM Evaluation of recurrence of periodontal disease after treatment in obese and normal weight patients: two-year follow-up. J Periodontol. 2020;91:1123-31.

37. Dimaisip-Nabuab J, Duijster D, Benzian H, Heinrich-Weltzien R, Homsavath A, Monse B, Sithan H, Stauf N, Susilawati S, Kromeyer-Hauschild K. Nutritional status, dental caries and tooth eruption in children: a longitudinal study in Cambodia. Indonesia and Lao PDR BMC Pediatr. 2018;18:300.

38. Cagetti MG , Wolf TG, Tennert C, Camoni N, Lingström P, Campus G. The Role of Vitamins in Oral Health. A Systematic Review and Meta-Analysis. Int J Environ Res Public Health. 2020, 17:938.

39. Janem WF, Scannapieco FA, Sabharwal A, Tsompana M, Berman HA, Haase EM, Miecznikowski JC, Mastrandrea LD. Salivary inflammatory markers and microbiome in normoglycemic lean and obese children compared to obese children with type 2 diabetes. PLOS ONE. 2017;12:e0172647.

40. Arrica M, Carta G, Cocco F, Cagetti MG, Campus G, lerardo G, Ottolenghi L, Sale S, Strohmenger L. Does a social/behavioural gradient in dental health exist among adults? A cross-sectional study. J Int Med Res. 2017:45:451-61.

41. Campus G, Cagetti MG, Senna A, Sacco G, Strohmenger L, Petersen PE. Caries prevalence and need for dental care in 13-18-year-olds in the municipality of Milan. Italy Community Dent Health. 2008;25:237-42.

42. Su H, Yang R, Deng Q, Qian W, Yu J. Deciduous dental caries status and associated risk factors among preschool children in Xuhui District of Shanghai. China BMC Oral Health. 2018:18:111.

43. Obregón-Rodríguez N, Fernández-Riveiro P, Piñeiro-Lamas M, SmythChamosa E, Montes-Martínez A, Suárez-Cunqueiro MM. Prevalence and caries-related risk factors in schoolchildren of 12- and 15-year-old: a cross-sectional study. BMC Oral Health. 2019;19:120.

\section{Publisher's Note}

Springer Nature remains neutral with regard to jurisdictional claims in published maps and institutional affiliations.
Ready to submit your research? Choose BMC and benefit from:

- fast, convenient online submission

- thorough peer review by experienced researchers in your field

- rapid publication on acceptance

- support for research data, including large and complex data types

- gold Open Access which fosters wider collaboration and increased citations

- maximum visibility for your research: over $100 \mathrm{M}$ website views per year

At BMC, research is always in progress.

Learn more biomedcentral.com/submissions 